symptom, there were well marked reypiratory undalations in the pulse tracing of the right radial artery.

The destructive pnenmonia which follows presenre on the bronchus was observed in six of the twenty cases. This destructive pneumonia may be mistaken for malignant disease of the lung, or for ordinary phthisis.

In one necropsy an aneurysm, involving the extra-pericardiac portion of the ascending aorta, had compressed the right bronchus, and had led to consolidation of the upper lobe of the right lang. During life the patient, a woman, had suffered from hremoptysis, slight stridor and exhanstion, with marked codems of the head, nock, and upper extremities. There was dulness over the nanubrium, and the usual signs of consolidation of a considerable portion of the right lung. There was no pulsation to be seen or felt, and no pain had ever been experienced; in addition, there was no fever during the time she was under observation. The balance of evidence was thought to be in favour of malignant growth, but at the necropsy an enormous aneurysm, with very thick walls, was found. It is well to remember that aneurysm is far more common than malignant growth in the mediastinum or of the lung. I have met with two cases of primary sarcoma of the lung during the time in which I have met with twenty cases of thoracic aneurysm.

This pneumonia is a very impor tant pressure-symptom; it may affect either the upper or lower lobe of the lung, and helps to localise a thoracic aneurysm, as in the following case. A man with an aneurysm of the femoral artery was operated on by Mr. Bennett May, the external iliac vessel being tied. He complained immediately after of pain in his chest, and a few months later presented signs of phthisis at the left apex. The consolidation of the left lung advanced; but, unlike what is usually seen in ordinary phthisis, the right lung was healthy, while the left was extensively consolidated. The aneurysm was supposed to be situated in the descending portion of the arch of the aorta, and to be growing forwards and compreesing the left bronchus, and this was found to be its exact position at the post-morlem examination.

In malignant disease the profound exhaustion which rapidly supervenes is very characteristic ; in addition, there is little if any fever, while in the consolidation resulting from pressure on the bronchus an irregular pyrexia is almost invariably present. In one case malig. nant disease of the upper lobe of the left lung was diagnosed; a day or two later a systolic bruit was heard in the interscapular region close to the spine. This threw a little doubt upon the diagnosis. Was the bruit due to pressure on the 2orts by the growth; or was there an aneurysm compressing the left bronchus and leading to a con. solidation of the left upper lobe? The absence of fever and the very marked exhaustion supported the diagnosis of malignant growth which was found to be present at the post-mortem examination. In four cases aortic regurgitation was present in addition to the aneurysm, probably being brought about by the same cause. In one case a donble Eruit was present at the base of the heart, with capillary pulsation but it was found after death that the aortic valves were perfectly competent, so that a diseased aorta alone can produce these conditions. In this case, also, the heart was not enlarged, only being displaced ; it seems that aneurysm, unless complicated with insufficiency of the aortic valves, does not lead to cardiac hypertrophy. A systolic bruit was heard in thirteen of the cases, in three no murmur at all. In two cases embolic phenomena were present, in both a left hemiplegia. In one case there was, in addition, embolism of the central artory of the retina on the same side, leaving well-marked atrophy of the disc. Nineteen of the twenty cases were aneurysms of the arch of the aorts outside the pericardium; one was innominate.

I have met with one case of acute aneurysmal dilatation of the intrapericardial portion of the aorta cansing death by perforation and hamorrhage into the pericardium. This was in a case of nlcerative endocarditis. The aneurysm was not diagnosed during life. In five cases the diagnosis could be made by inspection and palpation of the chest wall, there being evident bulging and pulsation; in fifteen there was neither of these symptoms. In nineteen of the twenty cases there was dulness on percussion over the manubrium or at the side of this portion of the sternum, attention being directed to this region by the patients' complaint of pain there. This region of the chest is often overlooked. It is a good rule to percuss the sternum in every case of chest-pain in men.

There is no such thing as mediastinal dulness in the healthy state, the note of the sternum in health being resonant, although there is no lung behind the first portion of it. Dulness over the manubrinm sterni is pathological, and means in the majority of cases mediastinal tumour, aneurysm being by far the commonest form. Tufnell's plan of treatment, together with the administration of iodide of potassium, gave great roliof in twelve cases. In two caces under this treatment the duinees almost diseppeared, the proesure symptoms complotoly so, and the diagnosis of aneurysm could not have been made withont a knowledge of the previous condition. The iodide was given in large doees, commoncing with ton grains, and increasing to a dose of a drachm or more, eccording to the tolerance and effects. In two or three cases the iodide 800 med to do harm, the pulse becoming very quick. Aconite in these cases suited bettor. Electrolysis was per. formed in one case with temporary relief.

\section{ANTIPYRIN IN SUNSTROKE.}

Bर Surazos G. A. HARRIS, M.R.C.S.E., L.R.C.P.Lond., B.M.S., Civil Burgeon, Simla.

THe following notos of a case of the hyperpyrexial form of insclation, which came under my observation at the Calcutta General Hospital, and which was in part treated with antipyrin, is of some interest. I believe it was one of the first, if not the first, case of insolation in which antipyrin was used to reduce the high temperature; at least, I have not seen any record of a previous case, though I know subsequent observations in tho United States of America were recorded in which antipyrin was used successfully to combat the hyperpyrexis of sunstroke. I regret that my own subsequent experi. ence did not confirm the hopes raised by the successful issue of the present case; but I think this was in part due to the doses being too small.

W. S., an American seaman, aged 40, was brought to the General Hospital, Calcutta, very shortly after 11 A.M., on May 19th, 1885. When admitted he was perfectly unconscious, and the only history obtainable was that ho had been seen early that day visiting several ships lying in port, and was known to have been drinking freely on several of these ships. Shortly before he was brought to the hospita\}, he had been found lying insensible on the Strand Road, which runs parallel with the River Hooghly.

On admission the temperature was $108^{\circ} \mathrm{F}$., at $11.15 \mathrm{~A}$.M., in the month and rectum. The patient was perfectly unconscious, with labonred and stertorous breathing; his face was markedly cyanotic; the akin of the whole surface was harsh, dry, and burning hot; the eyes were red and suffused, and both pupils contracted to a pin's point; there was a sweetish, sickly odour about the breath; the pulse was full and bounding; he was constantly throwing his arms about and groaning. There were a few superficial wounds on the scalp, filled with mud and gravel, and probably caused by falling on the ground when he first became insensible. Shortly after admission he vomited some undigested food and bilious-looking fluid, which smelt strongly of alcohol.

The patient's clothes being removed, he was at once well douched with cold water, given a large enems of iced water, then pat into a cold bath, and 10 grains of the neutral sulphate of quinine injected into his arm. Whilst in the bath his bowels acted freely. He was kept in the bath about ten minutes, ice being applied to the shaven head, and, before he was taken out, a drop of croton-oil was put on the back of his tongue. After the cold douche and the enems, the tempers. ture fell to $165^{\circ}$, and in the bath and after removal it kept on falling until 2.30 P.4., by which time it had fallen to 101\%. The cold bath had not boen repeated, but a largo sheet which was kept con. stantly wet with cold water was wrapped round him, and evaporation encouraged by constant fanning. Ice had been constantly applied to the hesd, but he had in no way regained conscionsness. Small quantities of Brand's essence vere put between his lips, but very little was swallowed. The convulsive twitching of the arms and legs was incessant, and there was the profoundest insensibility. The con. junctivæ and cornex conld be freely touched, and shouting into his ears produced no response. The pulse was 128, and of a running character ; the breathing continned stertorons. On any attempt being made to flex or extend the limbs they showed marked muscular rigidity with resistance. At 3.30 P.M. the temperature was $103.5^{\circ}$, and was apparently rising, notwithstanding the constant application of cold to the surface, so I determined to give antipyrin a trial, and 20 grains were dissolved in water and injected subcutaneously, and at 5 P.M. I repested this measure. In spite of this, the tempersture continued to rise, and at 5.45 P.M. Was $106^{\circ}$ in the rectum. At 6.10 P.M. the temperature was still $106^{\circ}$ in the rectum, and 30 grains of antipyrin were given by the mouth, and by 6.30 P.M. - that is, in twenty minutes - the temperature had fallen from $106^{\circ}$ to $102^{\circ}$. At 7.10 P.M. the 30-grain dose of antipyrin was repeated by the mouth; at 8.10 P.M. 15 grains were given by the mouth, and repeated at 9 P.M. and at 11 P.M. Subsequent to these big doses, the temperature did not 
rise above $103^{\circ}$, and by 10 P.M. it had fallen to $100^{\circ}$, and at midnight was $99^{\circ}$, and on the morning of May 20th was normal. Altogether, between 3.30 P.M. and 11 P.M., the patient had taken in all 145 grains of antipyrin (or nearly $2 \frac{1}{2}$ drachms). After the first big dose by the mouth, about 6.45 P. M., he seemed very decidedly better, answering to his name, and asking for milk, and by 8 P.M. he was able to talk sensibly and quietly, and the twitchings above mentioned had entirely stopped. The pupils were normal and responded, and the pulse was 120, soft and compressible. He had been sleeping off and on, but it was deemed advisable to give him a draught of bromide of potassium and chloral, 20 grains of each. The accompanying chart shows graphically the temperature curre. The subsequent history

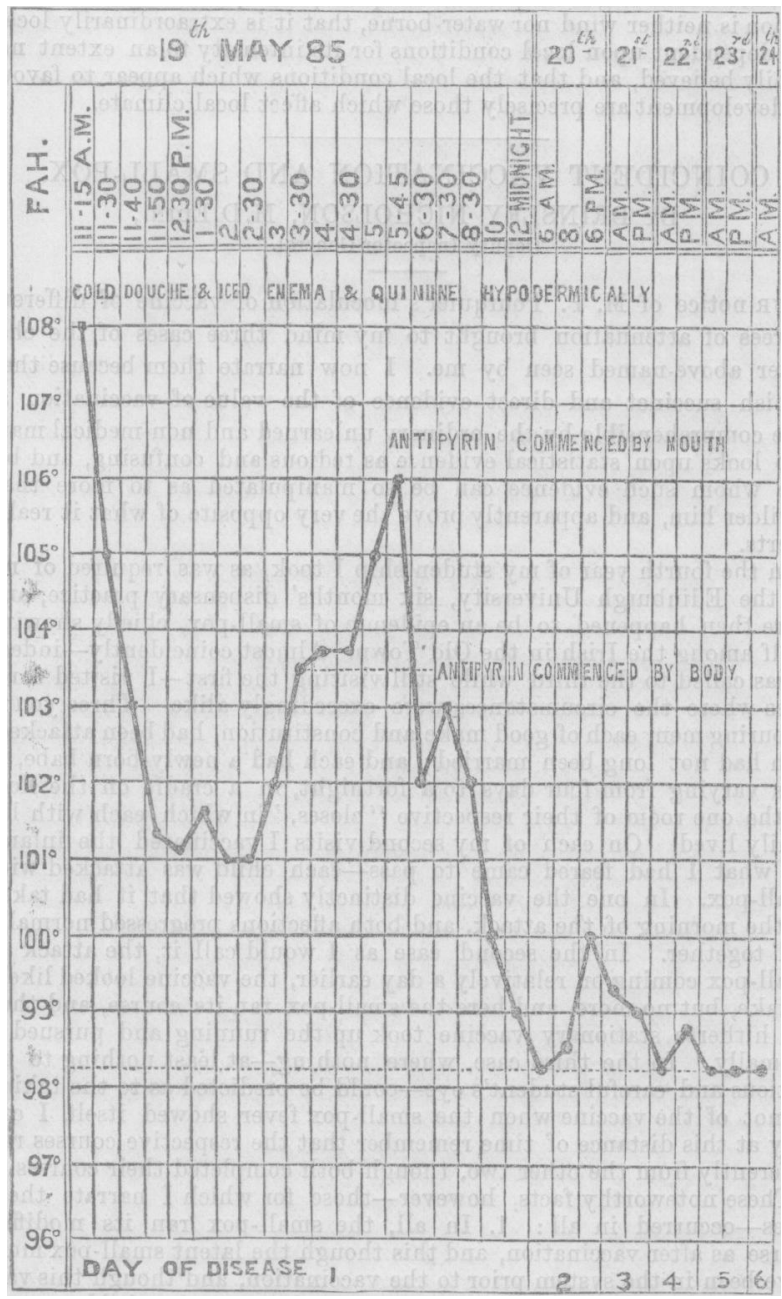

was one of uninterrupted convalescence; strength and appetite gradually returned; the temperature showed no disposition to rise above $100^{\circ}$, and no nervous sequelæ reinained. On June 7 th he was discharged well.

REMARKS. - I was almost constantly with the patient, and have no doubt in my own mind that the two doses of antipyrin of 30 grains each, given at 6.10 P.M. and 7.10 P.M., added to the two doses of 20 grains each given subcutaneously some hours previously, had a very decided effect in lowering the temperature, and thereby obviating the tendency to death, and that the subsequent doses of antipyrin above detailed materially aided in subduing and checking the hyperpyrexial tendency.

If I had a similar case to treat again, I would not hesitate to give 40 grains or even $1 \mathrm{drachm}$ of antipyrin in one dose, guarding it, if necessary, with alcohol and minute doses of atropine to lessen the depression which such a large single dose might produse; and, thus guarded, I would repeat the dose as often as I considered necessary. Although there may be very considerable doubt amongst the profes- sion as to continuously employing powerful antipyretics, as antipyrin, kairin, resorcin, salicylic acid, etc., in reducing the temperature of pneumonia, enteric fever, tuberculosis, etc., seeing that the mere pyrexia in these diseases is of itself rarely fatal, and we are as yet but on the outskirts of the inquiry as to whether the mere reduction of the temperature in these and other pyrexial diseases always cuts short the disease and lessens the tendency to complications, still there can be little, if any, doubt that hyperpyrexia ${ }^{1}$ must be cut short speedily to ensure recovery. Whether the means adopted to attain this very necessary end be the application of cold externally (by which I include the giving of enemata also) or the giving of drugs internally, the object is the same, and I think we are bound to leave nothing untried.

I have no experience of the newest candidate amongst antipyretic drugs, phenyl acetanilide or "antifebrin," but, according to Drs. Kahn and Hepp, assistants in Dr. Kussmal's Clinic in Strasburg, its action is four times more powerful than antipyrin-that is, 5 grains of acetanilide (or antifebrin) are equal to 20 grains of antipyrin in time of appearance, duration, and magnitude of their antipyretic action. Antifebrin also is said to cause less depression, and to be safer than antipyrin. I should think that antifebrin well merits a trial in all cases of hyperpyrexia, and especially in the hyperpyrexial form of insolation which is unfortunately so frequently seen amongst soldiers and sailors in our large garrison towns and Indian seaports.

I cannot explain why the temperature continued to rise in my case, notwithstanding cold douching and wet packing; nor can I explain why the antipyrin should have acted better by the mouth than subcutaneously.

\section{ABSTRACTS OF LECTURES}

on

\section{A L A R I L F E V R S.}

Bx W. NOR TH, B.A., F.C.S.,

Research Scholar of the Grocers' Company.

Lecture II. - Local Conditions Affecting their Distribution as Studied in the Province of Rome.

Is the previous lecture the general relation of malaria to latitude, altitude, water, and climate, have been shown to hold good for a continent, for an individual country, and for a province of that country; it remains to show how far these relations hold for much smaller areas. This involves consideration in detail of localities, and with regard to each the following points demand especial attention:

1. Local conformation of the soil. 2. Constitution of the soil. 3 . Water. 4. Altitude. 5. Cultivation. 6. Population. 7. Meteorology. 8. Drinking water.

Local Conformation of the Soil. - The peculiar nature of the Roman Campagna, and the fact that it is by no means a plain, in the generally accepted sense of the word, may be illustrated by the following examples.

The neighbourhood of the Isola Farnese is exceedingly broken up by streams running in valleys with almost precipitous walls, often fifty mètres and more in height, of more undulating country, but still very broken; the neirhbourhood of Tre Fontane to the south of Rome affords a good example; here there are valleys whose bottoms are not more than 12 to 16 metres, and whose sides may rise to 50 and even 60 mètres above sea-level. The streams which flow through these valleys are, for reasons to be considered later, liable to frequent flood, and deposit an enormous amount of mud and silt.

Of true plain, the valley of the Tiber, the Pontine region, and the low land on the coast-line, may be cited as the best examples.

Constitution of the Soil and Water.-It has been shown repeatedly that geology has little to do with malaria, except in so far as it affects the physical nature of the soil. The fact that the greater part of the Roman Campagna is volcanic is of material importance to the subject, inasmuch as it has a great influence on the distribution of the water. Underlying the surface-soil there is frequently an almost impervious layer of littoid tufa, full of saucer-like depressions, which hold water and render the soil with which they are filled and hidden wet and boggy. In some cases these depressions are crater-like and of large size, having once been, to all appearance, volcanic lakes. These larger depressions are found chiefly round the base of the extinct volcanoes of Albano and Bracciano ; the best example, perhaps, is that of the Val d'Ariccia, below Albano, which is nearly a mile across, exceedingly 1 By this I mean any temperature above $105.5^{\circ}$ or $106^{\circ}$. 